\title{
Optimized Blade Design of Counter-Rotating-Type Pump-Turbine Unit Operating in Pump and Turbine Modes
}

\author{
Jin-Woo Kim, ${ }^{1,2}$ Jun-Won Suh, ${ }^{2}$ Young-Seok Choi $\mathbb{D}^{1},{ }^{1,2}$ Kyoung-Yong Lee $\mathbb{D}^{\mathbb{D}},{ }^{2}$ \\ Toshiaki Kanemoto, ${ }^{3}$ and Jin-Hyuk Kim $\mathbb{1}^{1,2}$ \\ ${ }^{1}$ Advanced Energy and Technology, University of Science and Technology, 217 Gajeong-ro, Yuseong-gu, \\ Daejeon 34113, Republic of Korea \\ ${ }^{2}$ Thermal \& Fluid System R\&D Group, Korea Institute of Industrial Technology, 89 Yangdaegiro-gil, Ipjang-myeon, \\ Seobuk-gu, Cheonan-si, Chungcheongnam-do 31056, Republic of Korea \\ ${ }^{3}$ Institute of Ocean Energy, Saga University, 1-Honjo Machi, Saga-shi, Saga 840-8502, Japan
}

Correspondence should be addressed to Jin-Hyuk Kim; jinhyuk@kitech.re.kr

Received 20 October 2017; Accepted 26 February 2018; Published 3 April 2018

Academic Editor: Jingyin Li

Copyright (C) 2018 Jin-Woo Kim et al. This is an open access article distributed under the Creative Commons Attribution License, which permits unrestricted use, distribution, and reproduction in any medium, provided the original work is properly cited.

In this study, a counter-rotating-type pump-turbine unit was optimized to improve the pump and turbine mode efficiencies simultaneously. Numerical analysis was carried out by solving three-dimensional Reynolds-averaged Navier-Stokes equations using the shear stress turbulence model. The hub and tip blade angles of the rear impeller (in the pump mode) were selected as the design variables by conducting a sensitivity test. An optimization process based on steady flow analysis was conducted using a radial basis neural network surrogate model with Latin hypercube sampling. The pump and turbine mode efficiencies of the unit were selected as the objective functions and they combined into a single specific objective function with the weighting factors. Consequently, the pump and turbine mode efficiencies of the optimum design increased simultaneously at overall range of flow rate, except for low flow rate of turbine mode, compared to the reference design.

\section{Introduction}

Currently, the demand for renewable energy development is drastically increasing worldwide because of global climate change and depletion of fossil fuels. Renewable energy is a reliable source of energy including hydropower, wind energy, solar power, geothermal energy, solar heat, and tidal energy. Pumped-storage hydroelectricity (PSH), which is one form of the hydropower, has high energy density and generating efficiency compared with other renewable energy development. The PSH stores energy in the form of water by pumping the water to an upper reservoir. When electric power is demanded from the facilities, the power is generated by releasing the water, which was stored in an upper reservoir, with turbine. When the power is low demanded (night or on weekends), the upper reservoir is recharged by using excess electric power with pump. As a type of pump-turbine technology used for the PSH, a counter-rotating-type pumpturbine unit has many advantages; however the disadvantage of the unit is that the efficiencies are very low, especially in the pump mode. Hence, the high design technology of a counterrotating-type pump-turbine unit, which can act as both the pumps and turbines, is required to solve the above problem [1].

Several studies have been conducted on the counterrotating-type pump-turbine unit to increase the performance and understand the internal flow mechanism of the unit by experimental and simulation methods [1-5]. In addition, Murakami and Kanemoto [6] studied the tandem impellers of the counter-rotating type pump unit operated in the turbine mode. Additionally, they studied the hydraulic efficiency and the internal flow conditions of the unit through experimental and numerical methods. As a result, the maximum hydraulic efficiency in the turbine mode is similar to one of the unit designed exclusively for the turbine mode. Kanemoto and Oba [7] invented unique double-rotational armatures coupled with the counter-rotating-type impellers/runners to suppress the unstable performance and cavitation throughout 


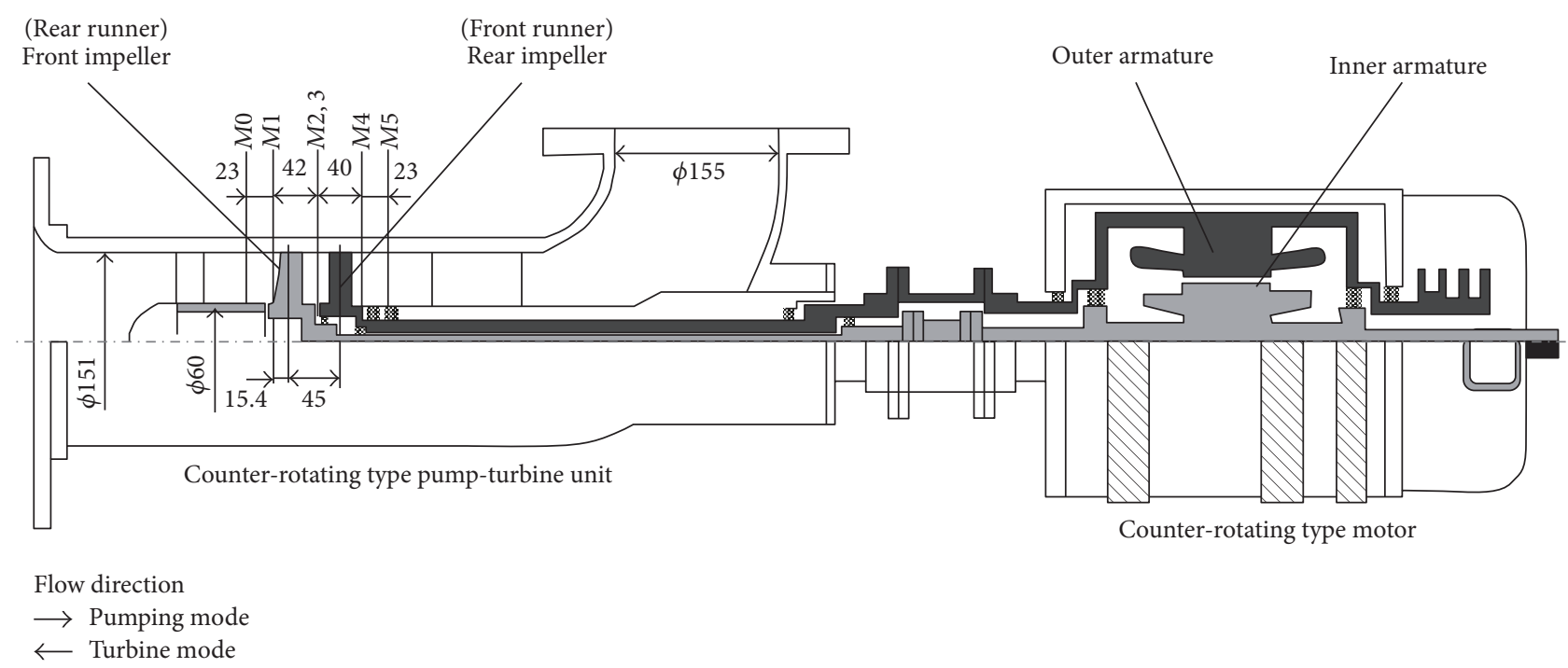

FIGURE 1: Counter-rotating-type pump-turbine unit [2].

the operating region. Cao et al. [8] studied the application of contra-rotating type rotors to reduce the rotational speed and pump size under the same specification of conventional axialflow pump through experimental and numerical methods. Similarly, several studies have been conducted on the mechanisms, internal flow characteristics, and hydrodynamic performance characteristics of the counter-rotating-type pumpturbine unit. However, none of the authors considered simultaneously increasing the pump and turbine mode efficiencies of the unit with respect to the variation in the blade angles.

In this study, a multiobjective optimization is proposed using the weighted-sum method to increase the pump and turbine mode efficiencies simultaneously using threedimensional incompressible steady-state Reynolds-averaged Navier-Stokes (RANS) simulations. As the main objectives of this study, the pump and turbine mode efficiencies of a counter-rotating-type pump-turbine unit are simultaneously increased using a multiobjective optimization method and a reasonable guideline is provided for appropriate design depending on the required performance. Finally, the effects of the variation in the blade angle on the pump and turbine mode efficiencies and internal flow field are analyzed in this paper.

\section{Counter-Rotating-Type Pump-Turbine Unit}

The reference design of the counter-rotating-type pumpturbine unit was obtained from another study [1]. The mass flow rate and rotational speed of each impeller/runner were selected to meet the fixed total head in the pump and turbine modes, respectively, as the design condition. The unit comprises front and rear impellers having five and four blades, respectively, based on the pump mode, as shown in Figure 1. Two sets of pump-turbine blades that are installed around the inner and outer axis, respectively, are driven by a counter-rotating motor-generator, as shown in Figure 1. The counter-rotating motor-generator is composed of an inner and outer armature with different poles and is capable of driving two axes with only one axial power by relying on the action and reaction mechanism during the driving. The tip clearance of the impellers/runners is established as $0.5 \mathrm{~mm}$. The counter-rotating-type rotors were installed on the counter-driving single shaft, comprising inner and outer armatures. Additionally, the unit can operate in the pump and turbine modes depending on the operating purpose. The hydrodynamic efficiencies for the reference design were evaluated as $77.03 \%$ and $81.26 \%$ in the pump and turbine modes, respectively, by the experimental study. Table 1 gives the detailed specifications of the reference design.

\section{Numerical Analysis Method}

Figure 2 shows the computational domain and methods for the numerical analysis. The mesh for the front and rear impeller/runner domains was constructed using approximately 510,000 and 420,000 nodes, respectively, based on the result of the mesh-dependency test, which was performed in the previous study [9]. The computational domain was constructed as a hexahedral mesh and the distance between the wall and the nearest node point was defined as a value of $y^{+} \leq 2$.

The numerical analysis was conducted by solving the three-dimensional steady-state incompressible RANS equations using the commercial code ANSYS CFX 14.5 [10]. A $k$ - $\omega$-based SST turbulence model discretized through finite volume method (FVM) and solved on hexahedral grids was used to analyze the flow characteristics of the turbulent flow. This model is known to predict the flow separation appropriately for adverse pressure gradients. The working fluid selected was standard water at $25^{\circ} \mathrm{C}$.

The boundary conditions of the computational domain were set as atmospheric pressure and mass flow rate at the inlet and outlet, respectively, as shown in Figure 2. The computational domain for the two impellers/runners consists of each single passage and was established to periodic boundary conditions. The stage average method was used as 
TABLE 1: Design specifications of the reference design.

\begin{tabular}{lccc}
\hline Diameter of blade $(\mathrm{mm})$ & 150 & Tip clearance $(\mathrm{mm})$ & 0.5 \\
Pump mode efficiency $(\%)$ & 77.03 & Turbine mode efficiency $(\%)$ & 81.26 \\
Designed mass flow rate at pump mode $\left(\mathrm{m}^{3} / \mathrm{h}\right)$ & 93.51 & Designed mass flow rate at turbine $\mathrm{mode}^{3}\left(\mathrm{~m}^{3} / \mathrm{h}\right)$ & 85.98 \\
Total rotational speed at pump mode $(\mathrm{r} / \mathrm{min})$ & 2,463 & Total rotational speed at turbine mode $(\mathrm{r} / \mathrm{min})$ & 1,675 \\
Number of blades (front impeller/rear runner) & 5 & Number of blades (rear impeller/front runner) & 4 \\
\hline
\end{tabular}

the interface condition to transmit information between the front and rear impellers/runners.

The validation assessment was conducted to check the accuracy of the numerical analysis by comparing the experimental results with the numerical analysis results of the reference design obtained from another study [11]. Figure 3 shows the validation assessment results for the power and efficiency with respect to the rotational speeds in the pump and turbine modes. The coefficients $P_{11}$ and $N_{11}$ were used to represent the power and rotational speed simultaneously in the pump and turbine modes, which are defined as follows:

$$
\begin{aligned}
P_{11} & =\frac{P}{D^{2} \times H^{3 / 2}} \\
N_{11} & =\frac{N_{t} \times D}{\sqrt{H}}
\end{aligned}
$$

where $N_{t}, D, H$, and $P$ represent the total rotational speed, diameter, total head, and power, respectively. As shown in Figure 3 [11], the numerical-simulation results for the power and efficiency are in good agreement with the experimental results throughout the range, except for low rotational speeds, where the flow in the turbine mode is especially unstable. Generally, the numerical results for the torque are in reasonable agreement with the experimental data, although the steady RANS analysis with the single passage domain is conducted with no consideration of the mechanical losses. In conclusion, the numerical results of this study are proven valid and reliable.

\section{Optimization Technique}

The objective of the optimization in this study is to maximize the pump and turbine mode efficiencies simultaneously $\left(\eta_{p}\right.$ and $\eta_{t}$, respectively), which are defined as follows:

$$
\begin{gathered}
\eta_{p}=\frac{\rho g H Q_{p}}{T_{p} \omega_{p}} \\
\eta_{t}=\frac{T_{t} \omega_{t}}{\rho g H Q_{t}},
\end{gathered}
$$

where $\rho, g, Q, T$, and $\omega$ represent the density, acceleration due to gravity, volumetric flow rate, blade torque, and angular velocity, respectively.

These objective functions, which are related to the performance of the counter-rotating-type pump-turbine unit, were integrated into a single specific objective function $F_{\text {eff }}$ by applying the weighted-sum method [12] in the optimization. The pump and turbine mode efficiencies were combined with
TABLE 2: Design variables and range.

\begin{tabular}{lcc}
\hline Design variables & Lower bound $\left(^{\circ}\right)$ & Upper bound $\left(^{\circ}\right)$ \\
\hline 4 B_hub & 0 & 4 \\
4 B_tip & 0 & 4 \\
\hline
\end{tabular}

weighting factors $\omega_{1}$ and $\omega_{2}$, which were selected as 1.0 , to increase the pump and turbine mode efficiencies simultaneously. The specific objective function $F_{\text {eff }}$ is defined as follows:

$$
F_{\mathrm{eff}}=\eta_{p} \times \omega_{1}+\eta_{t} \times \omega_{2} .
$$

In a previous study [11], the sensitivity analysis of the blade angles at the hub and tip profiles of the front and rear impellers/runners, which served as the design variable, was conducted using the two-level factorial design in the designof-experiment (DOE) [13]. The hub and tip blade angles of the rear impeller/front runner ( $4 \mathrm{~B} \_$hub and $4 \mathrm{~B} \_$tip, respectively) were selected as design variables, and their ranges were selected based on the result of the sensitivity analysis, as given in Figure 4 and Table 2.

For the optimization, reasonable design points within the range of the design variables need to be defined. Hence, twelve design points were selected using Latin hypercube sampling (LHS) [14], which is one of the DOE. The objective functions at these design points were evaluated using the three-dimensional steady-state RANS simulations.

The optimum design was obtained using a radial basis neural network (RBNN) surrogate model based on the objective function values of the generated twelve design points. In general, the basic concept of the RBNN is simulating the human functions of learning from experience and making predictions of optimal states using existing data. The main advantage of the RBNN is significant reduction in computational cost and time owing to the linear nature of the radial basis functions. This RBNN surrogate model is proven as a useful tool particularly for designing high-performance turbomachinery [15-17]. In addition, the effectiveness of these numerical optimization techniques has been already demonstrated as a practical tool to solve multiple problems for various hydraulic machineries in the previous works [18-22]. A sequential quadratic programming (SQP) [23] algorithm, which is one of the most successful methods for the numerical solution, was applied to determine the optimum design of the RBNN model.

\section{Results and Discussion}

Table 3 gives the results of the multiobjective optimization. Both the design variables were modified significantly with 


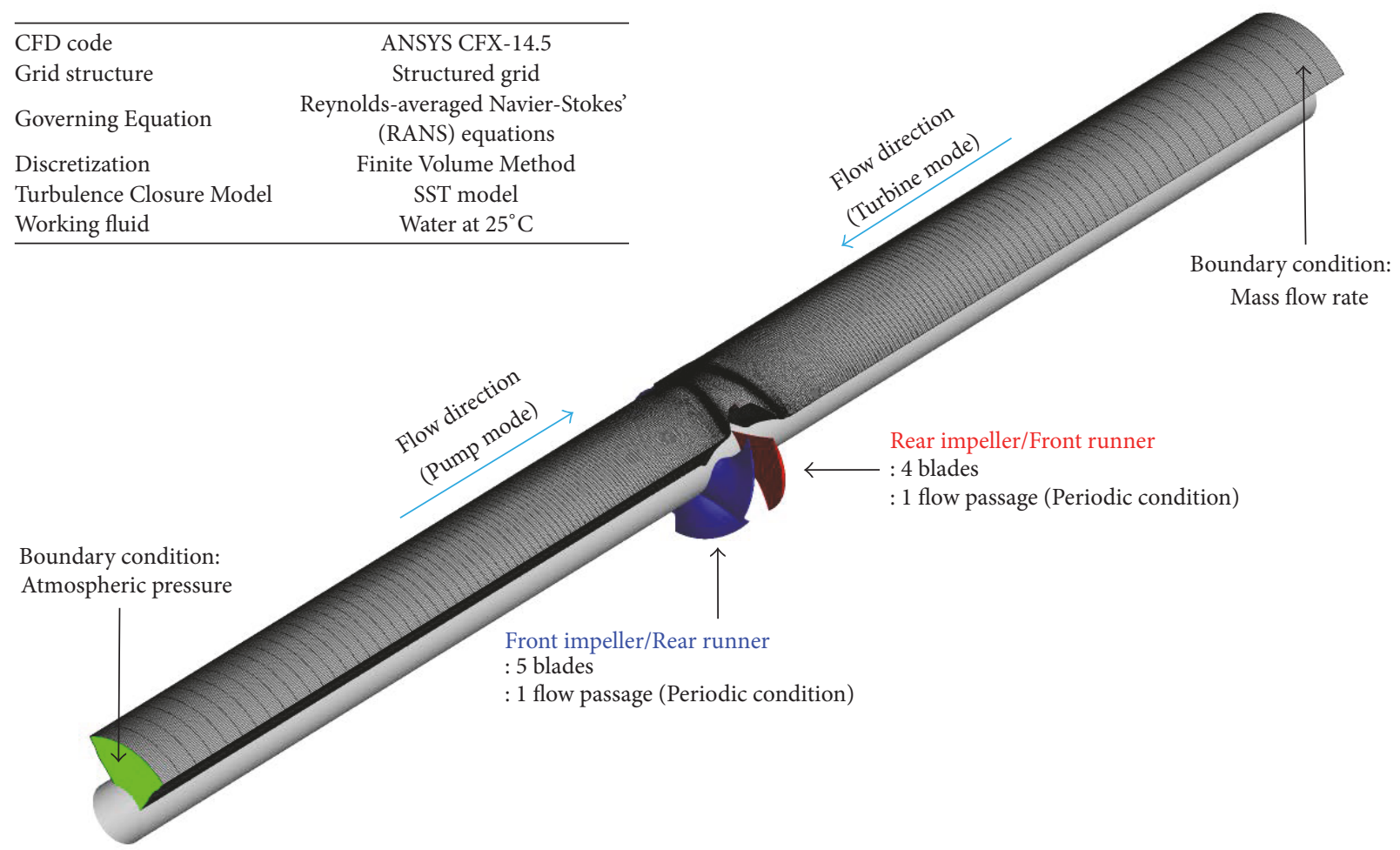

FIgURE 2: Computational domain and methods.

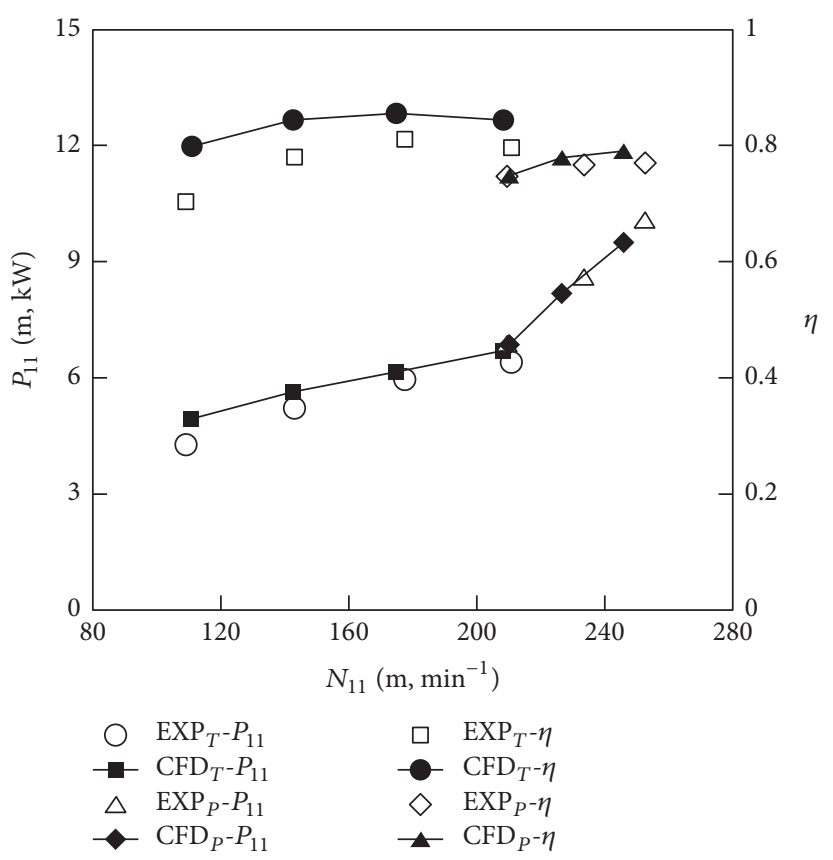

FIGURE 3: Validation assessment of the numerical results [11].

respect to the reference design, as shown in Figure 5. Figure 5 shows a three-dimensional mesh plot of the constructed RBNN surrogate model.

The optimum point, located at $(2.64,1.75)$ on the surface, is clearly seen in this figure. In Table 3 , the value of the specific objective function of the reference design calculated using the RANS analysis is 2.0. The specific objective function value of the optimum design is analyzed as 2.018 using the RBNN surrogate model and calculated as 2.017 using RANS analysis. Therefore, the relative error between the predicted 


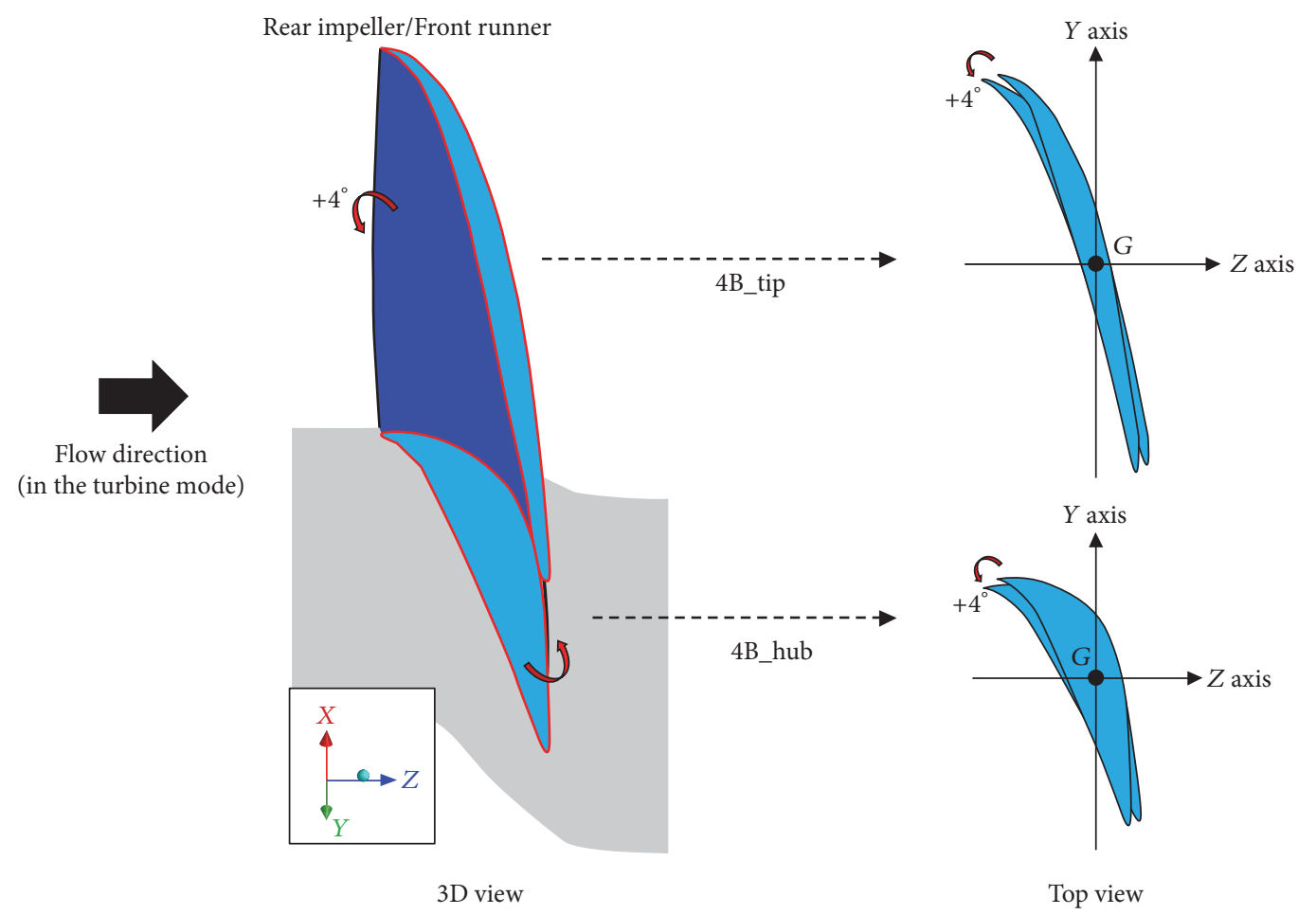

FIGURE 4: Definition of the design variables.

TABLE 3: Results of the multiobjective optimization.

\begin{tabular}{|c|c|c|c|c|c|c|c|c|c|c|}
\hline \multirow[t]{2}{*}{ Designs } & \multicolumn{2}{|c|}{ Design variables (deg.) } & \multicolumn{2}{|c|}{$\begin{array}{l}\text { Specific objective } \\
\text { function }\left(F_{\text {eff }}\right)\end{array}$} & \multirow{2}{*}{$\begin{array}{c}\text { Error (\%) } \\
- \\
\end{array}$} & \multirow{2}{*}{$\begin{array}{c}\text { Relative } \\
\text { improvement } \\
-\end{array}$} & \multicolumn{2}{|c|}{ Efficiency (\%) } & \multicolumn{2}{|c|}{$\begin{array}{c}\text { Relative improvement } \\
(\%)\end{array}$} \\
\hline & 4B_hub & 4B_tip & Surrogate & RANS & & & $\eta_{p}$ & $\eta_{t}$ & $\eta_{p}$ & $\eta_{t}$ \\
\hline $\begin{array}{l}\text { Reference } \\
\text { design }\end{array}$ & 0 & 0 & - & 2.0 & - & - & 78.78 & 85.65 & - & - \\
\hline $\begin{array}{l}\text { Optimum } \\
\text { design }\end{array}$ & 2.64 & 1.75 & 2.018 & 2.017 & 0.05 & 0.017 & 79.79 & 86.17 & 1.01 & 0.52 \\
\hline
\end{tabular}

values using the RBNN surrogate model and RANS analysis is only $0.05 \%$. The relative improvement of the specific objective function value using the RANS analysis between the reference design and optimum design was analyzed as 0.017 .

Figure 6 shows the sensitivity of the specific objective function to the variation in each design variable. $F_{\text {eff }}$ indicates the value of the specific objective function at the optimum point, and the result shows that the specific objective function is sensitive to both the design variables in a similar manner. Consequently, both the design variables are quite important for the specific objective function.

Figure 7 shows the results of the multiobjective optimization using the RBNN surrogate model. The results show the pump and turbine mode efficiencies of the objective functions for the reference design, the twelve design points obtained through LHS, and the optimum design. The result shows that both the pump and turbine mode efficiencies were increased considerably by $1.01 \%$ and $0.52 \%$, respectively, compared to those of the reference design, as given in Table 3.

The analysis of the flow field was conducted to understand the main reason behind the improvement in efficiency for the optimum designs. The analysis was conducted at each design flow rate by dividing the pump and turbine modes, as shown in Figures 8-10 (for the pump mode) and Figures 11-14 (for the turbine mode). Figure 8 shows the efficiency distribution for each impeller and entire unit of the reference and optimum designs in the pump mode. As shown in Figure 8, the efficiencies of the front impeller having five blades are similar, whereas the efficiencies of the rear impeller having four blades increased considerably to $1.57 \%$. Hence, the efficiency of the entire unit for the optimum design increased to $1.01 \%$ compared to the reference design, as discussed previously in Table 3. The results show that the variations in the design variables significantly affect the efficiency in the pump mode.

Figure 9 shows the static-pressure distributions in the streamwise location at 5, mid, and $95 \%$ spans on the suction and pressure surfaces of the rear impellers having four blades for the reference and optimum designs in the pump mode. The static pressures around the leading edge on the pressure sides for the optimum design slightly improved for all spans compared to the reference design. Furthermore, the static pressures on the entire range of the suction surfaces for the 


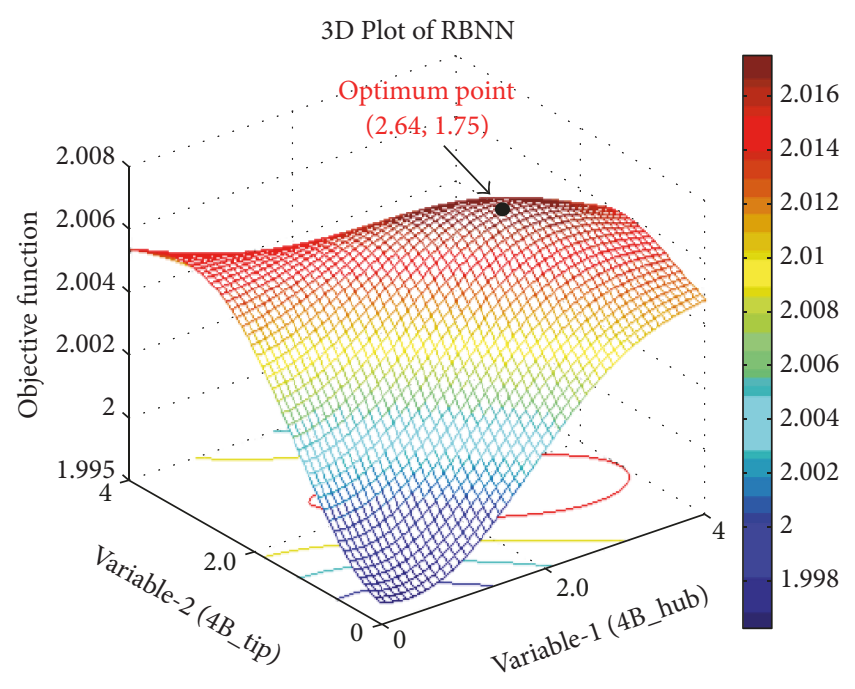

Figure 5: 3D surface plot for the RBNN model.

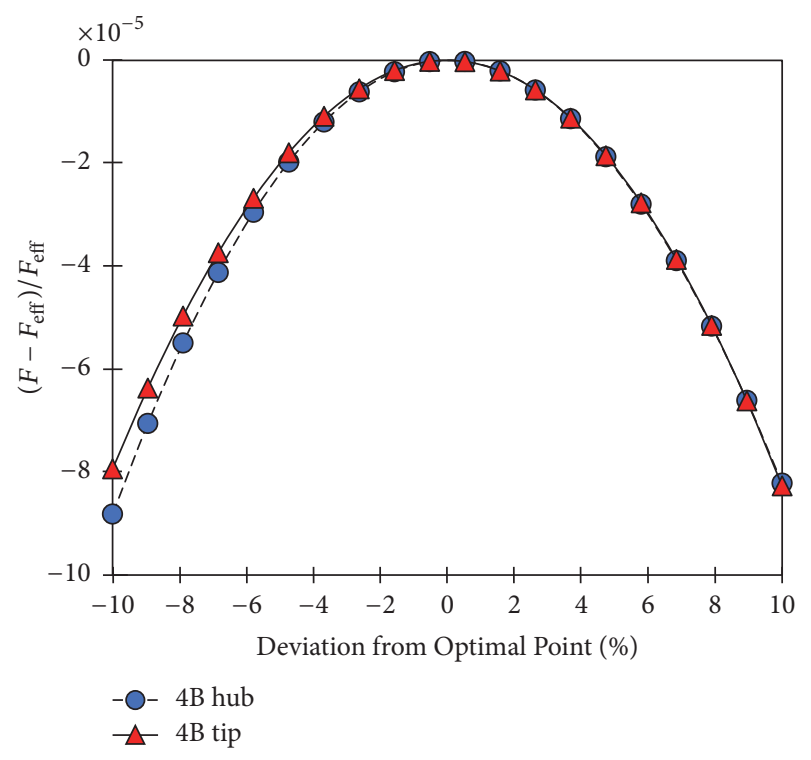

Figure 6: Sensitivity analysis results.

optimum design increased sufficiently for all spans compared to the reference design. Hence, the static pressures of the optimized rear impeller at most spans improved because of the optimization.

Figure 10 shows the static-pressure distributions in the blade-to-blade passages at the same spans, as those seen in Figure 9, for the reference and optimum designs. The staticpressure distributions for all the spans of the front impellers for the reference and optimum designs are almost similar. However, the low static-pressure zones on the suction side at all spans of the rear impellers for the optimum design reduced significantly compared to the reference design through the optimization, as previously shown in Figure 9. These results show that the pump mode efficiency improved because the incidence angles of the optimized impeller were properly aligned with the fluid inlet angle by varying the hub and tip blade angles.

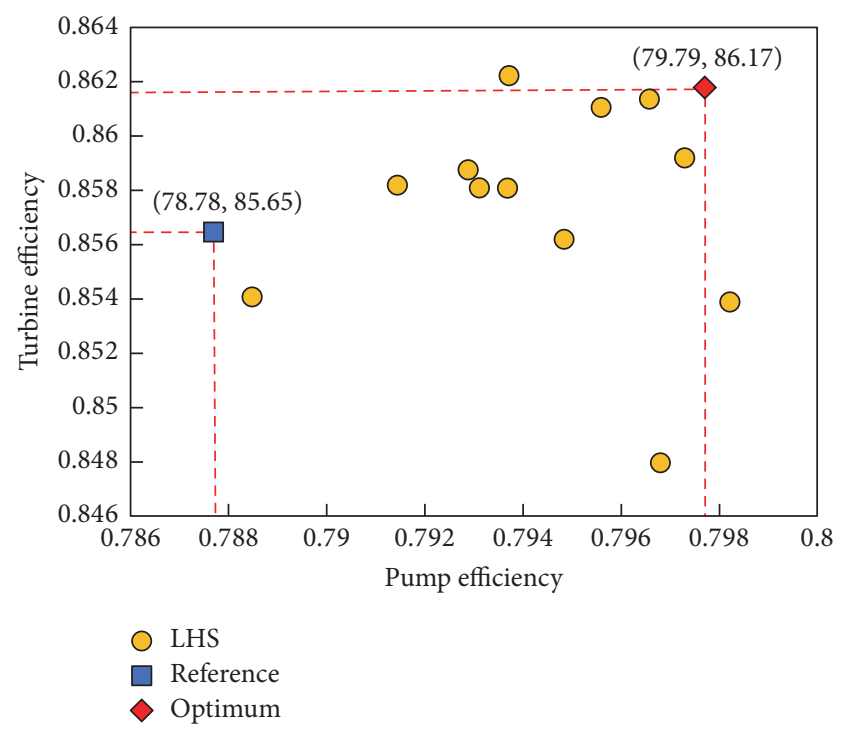

FIGURE 7: Results of multiobjective optimization.

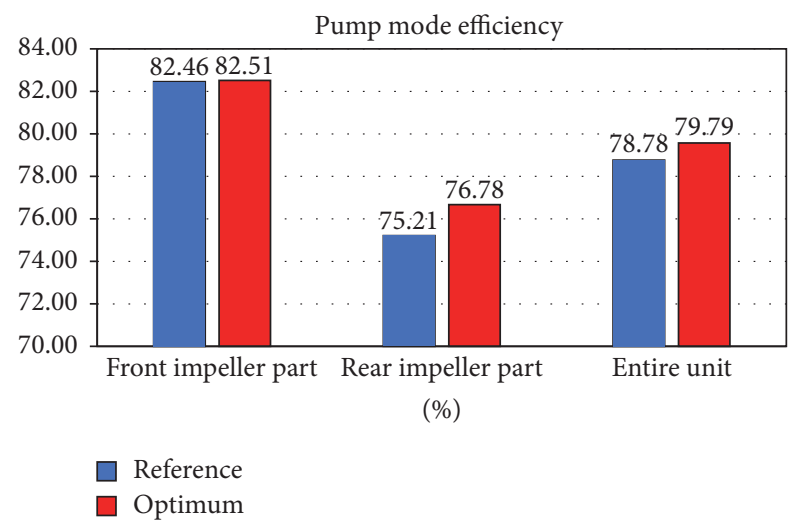

FIGURE 8: Efficiency distribution for each impeller and entire unit on the pump mode.

Figure 11 shows the efficiency distribution for each impeller and the entire unit for the reference and optimum designs on the turbine mode. Unlike the pump mode, the efficiencies of the front runner, which is an optimized runner having four blades, reduced to $1.45 \%$ compared to the reference design through the optimization. However, the efficiencies of the rear runner having five blades improved significantly to $1.97 \%$. The turbine mode efficiency of the entire unit for the optimum design increased to $0.52 \%$ compared to the reference design, as discussed previously in Table 3. In summary, the efficiencies for the optimum design increased not only in the pump mode but also in the turbine mode through the optimization.

Figure 12 shows the static-pressure distributions in the streamwise location at spans of 5, mid, and $95 \%$ on the suction and pressure sides of the front runners having four blades for the reference and optimum designs in the turbine mode. In general, the closed area filled with the staticpressure distributions is proportional to the output power of the turbine [24], and the closed area for the optimum 


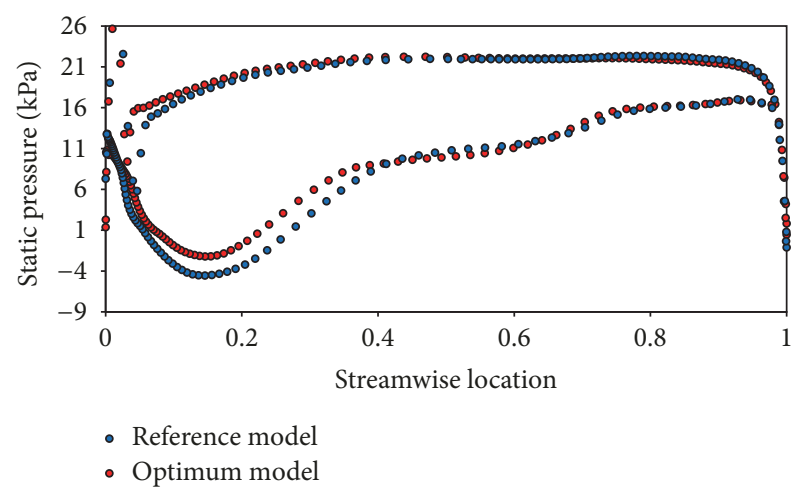

(a) At 5\% span

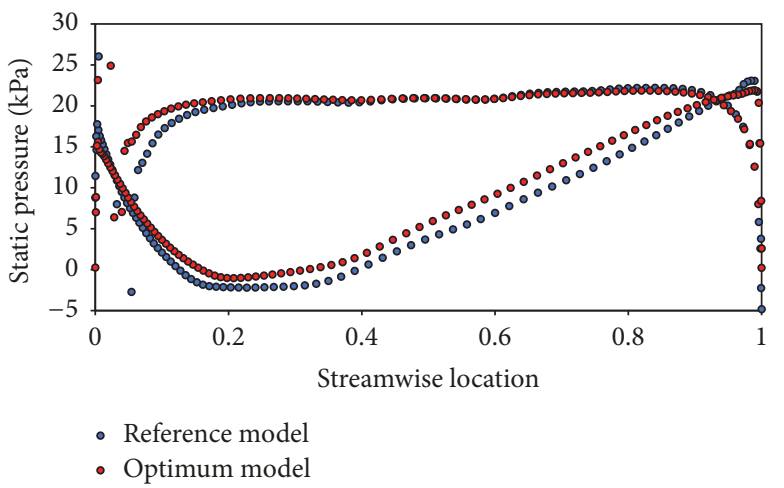

(b) At mid-span

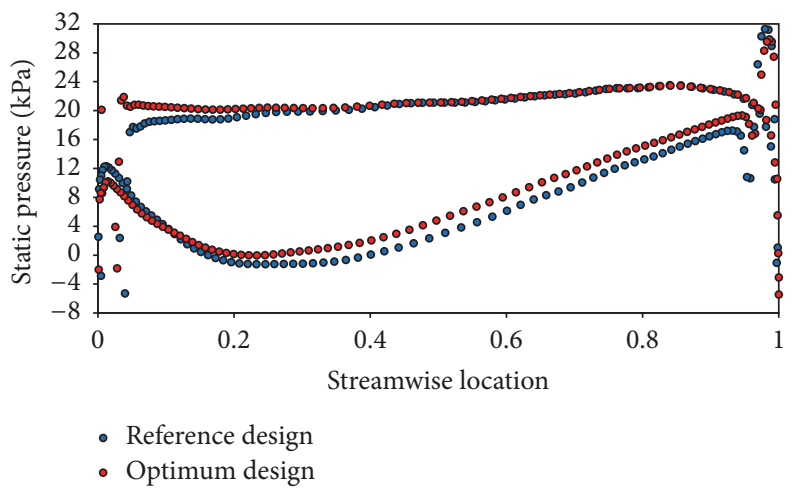

(c) At $95 \%$ span

FIGURE 9: Static-pressure distributions on the blade surfaces of the rear impellers.

design reduced slightly as shown in Figure 12. Hence, this result explains the reduced efficiency of the front runner in the turbine mode compared to the reference design as shown in Figure 11. Furthermore, the static pressures near the trailing edge on the pressure side for the optimum design improved slightly at all spans. Additionally, the negativepressure components on the suction side of the optimum design reduced slightly because the incidence angles changed because of the optimization.

Figure 13 shows the static-pressure distributions in the streamwise location at spans of 5 , mid, and $95 \%$ on the suction and pressure sides of the rear runners having five blades for the reference and optimum designs. The flow angle of the upstream region beyond the front runner for the optimum design changed because of the optimization when compared with the reference design. Hence, the closed area in the rear runners of the optimum design generally increased except in the suction side of the $5 \%$ span, particularly on the pressure side. These results contributed to the improvement in the turbine efficiency.

Figure 14 shows the velocity distributions around the trailing edge of the front and rear runners for the reference and optimum designs. Figure 14(a) shows the viewing points. As shown in Figure 14(b), the velocity distributions from the hub to tip in the front runner for the optimum design changed uniformly in comparison with the reference design. Based on the flow stabilization of the front runner region, the velocity distributions in the rear runner were largely uniform, and the locally high-velocity region near the tip decreased as shown in Figure 14(c). These results prove the enhancement in the turbine efficiency owing to the optimization.

Figure 15 shows the overall efficiency curves in the pump and turbine modes for the reference and optimum designs of a counter-rotating-type pump-turbine unit. As shown in Figure 15(a), which is analyzed for the pump mode, the entire efficiency distribution of the optimum design was improved remarkably compared to the reference design, especially at high flow rate. In the case of the turbine mode, the turbine mode efficiencies of the optimum design were increased generally in region of the high flow rate including design flow rate, in comparison with the reference design. On the contrary, the efficiencies at low flow rate show opposite results, as shown in Figure 15(b). As a result, the pump and turbine mode efficiencies of the optimum design were improved simultaneously at overall range of flow rate, except for low flow rate of turbine mode. Hence, it can be seen that the design technique suggested in this work is very useful for improving both pump and turbine efficiencies of the counterrotating-type pump-turbine unit.

\section{Conclusion}

In this study, a counter-rotating-type pump-turbine unit was optimized to maximize the pump and turbine mode 


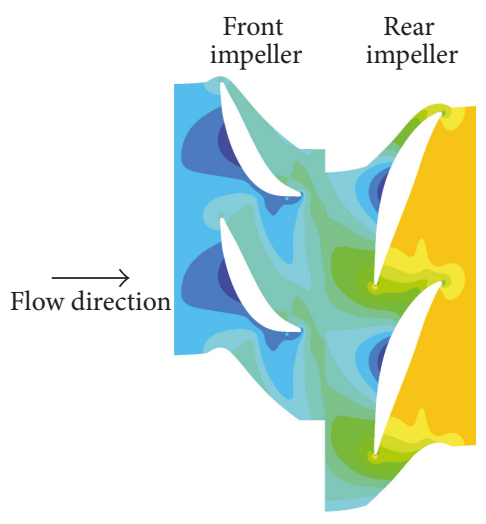

Reference

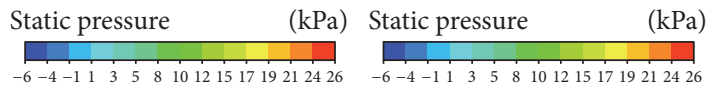

(a) At $5 \%$ span
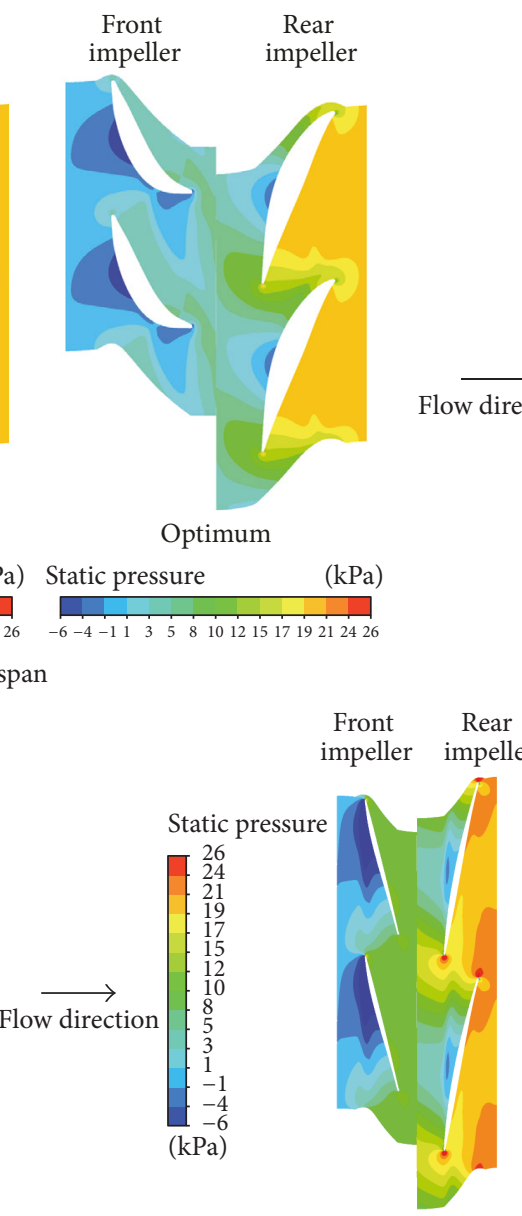

Reference

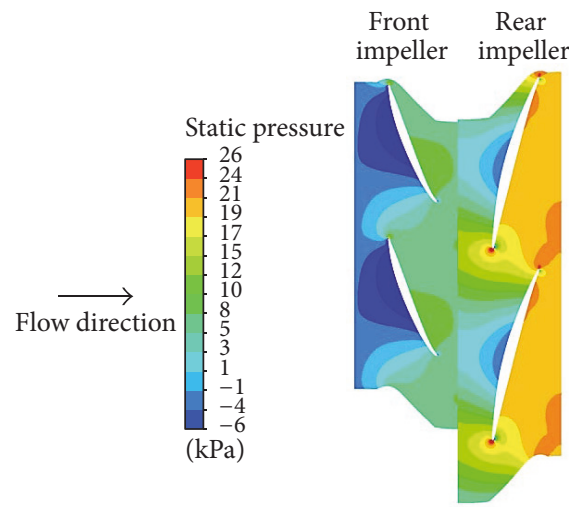

Reference

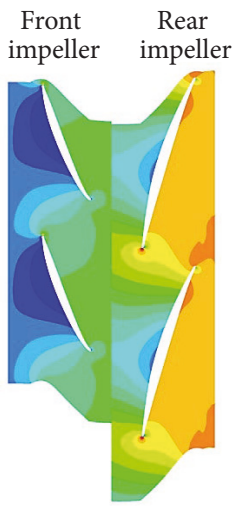

Optimum

(b) At mid-span

(c) At $95 \%$ span

FIGURE 10: Static-pressure distribution on the blade-to-blade passage.

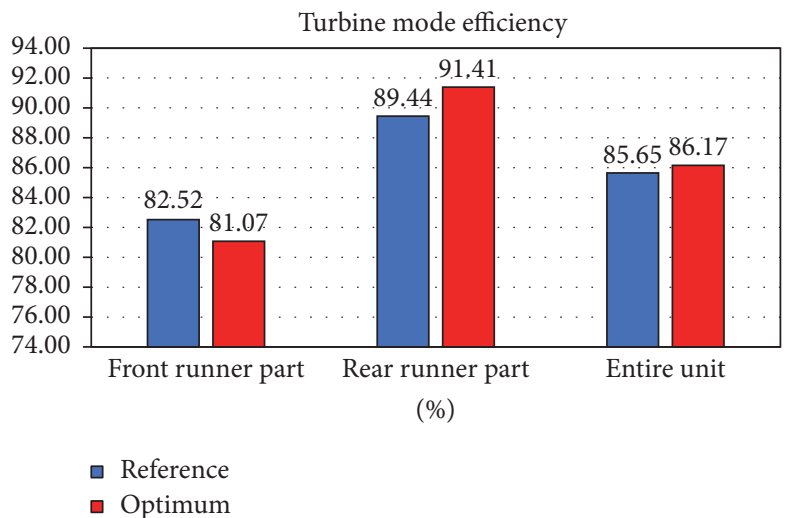

FIGURE 11: Efficiency distribution for each impeller and entire unit in the turbine mode.

efficiencies simultaneously using the RBNN surrogate model through three-dimensional steady-state RANS simulation. The multiobjective optimization using the weighted-sum method was conducted with two design variables based on the blade angles of the impeller/runner having four blades. The pump and turbine mode efficiencies of the optimized design were improved by $1.01 \%$ and $0.52 \%$, respectively, at design flow rate, compared to the efficiencies of the reference design. Additionally, the efficiencies in the pump and turbine modes of the optimum design were considerably enhanced throughout the entire flow rate, except for low flow rate of turbine mode. Consequentially, the improvement in the pump 


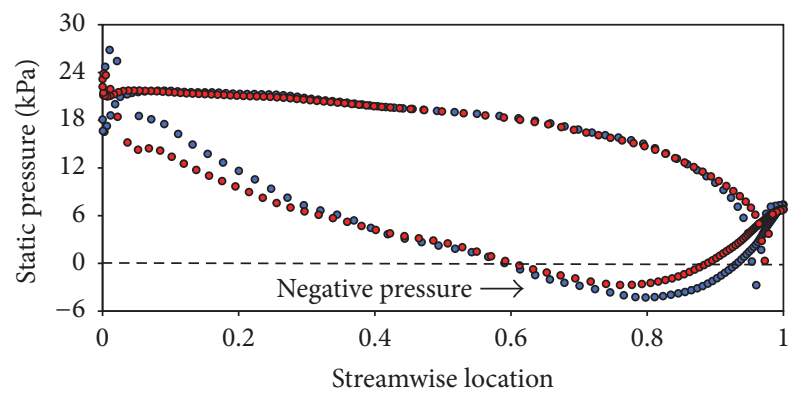

- Reference design

- Optimum design

(a) At $5 \%$ span

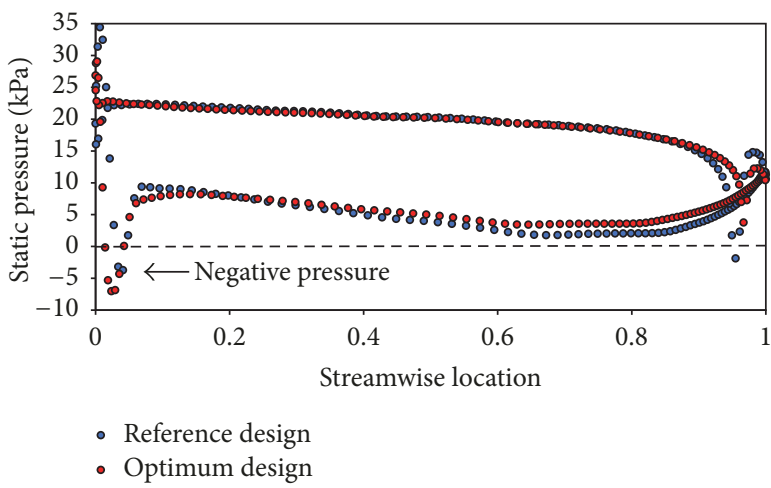

(b) At mid-span

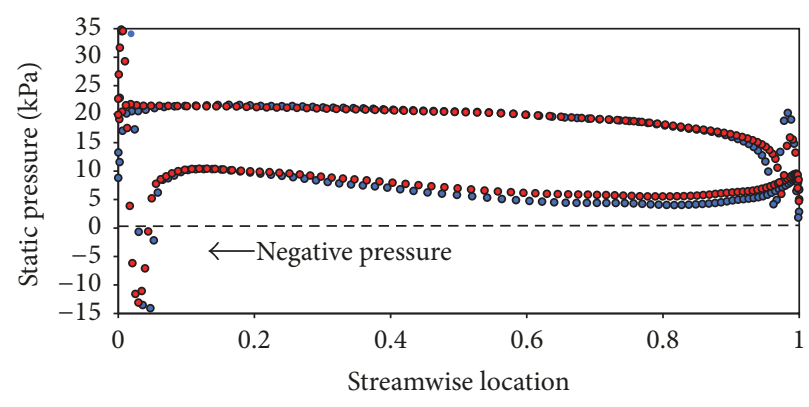

- Reference design

- Optimum design

(c) At $95 \%$ span

FIGURE 12: Static-pressure distributions on the blade surfaces of the front runners.

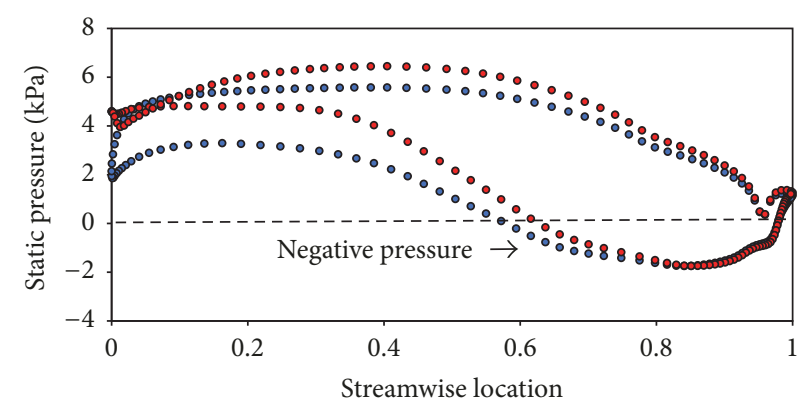

- Reference design

- Optimum design

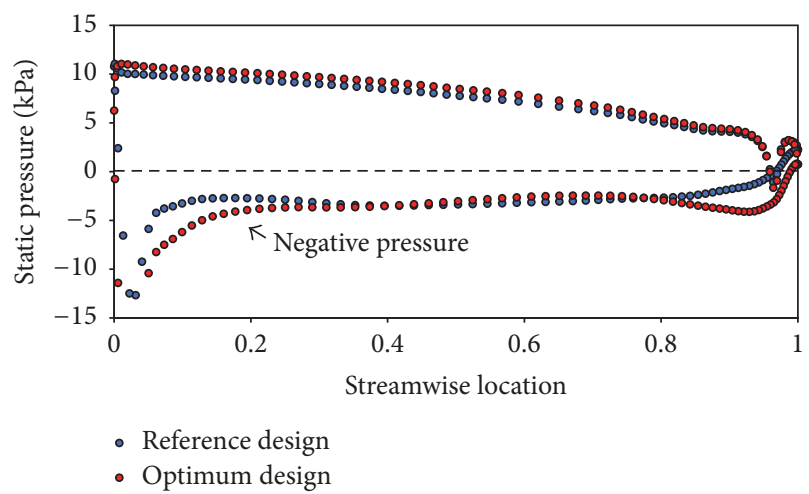

(b) At mid-span
- Optimum design

(a) At $5 \%$ span

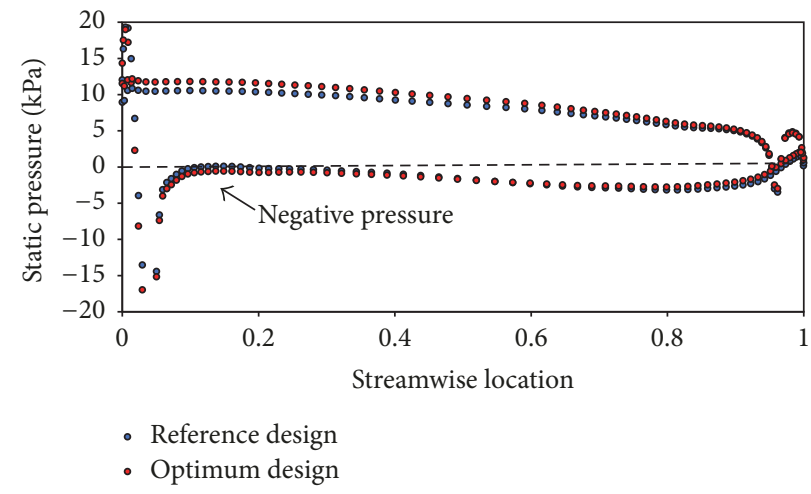

(c) At $95 \%$ span

FIGURE 13: Static-pressure distributions on the blade surfaces of the rear runners. 

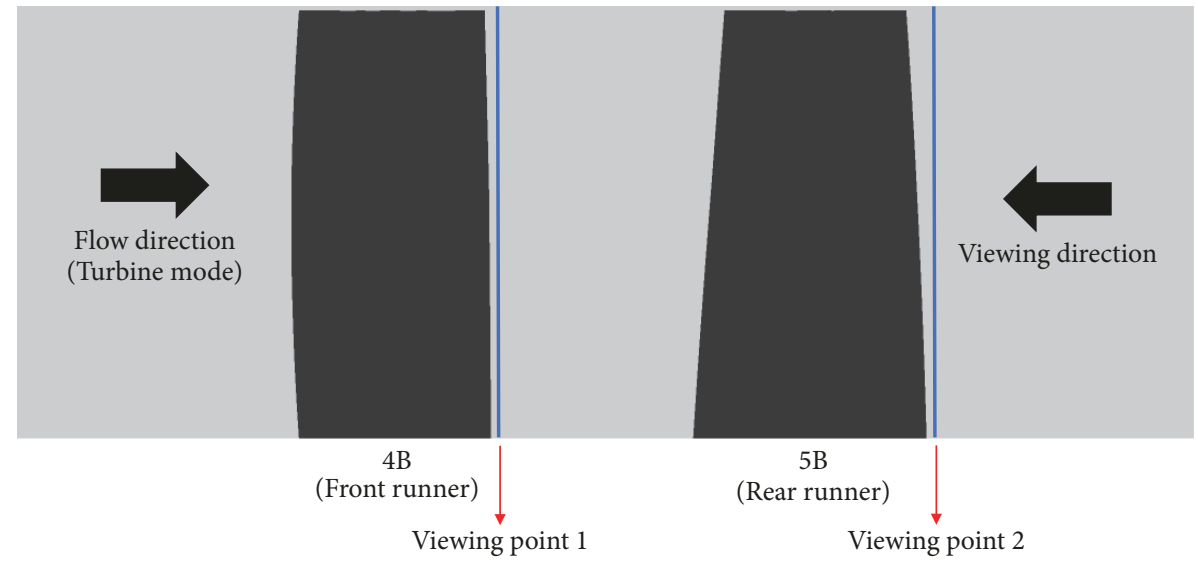

(a) Location of observation

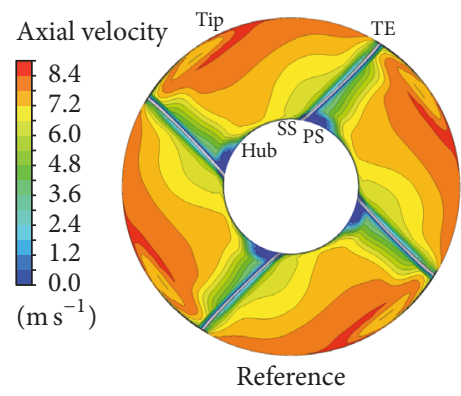

(b) Viewing point 1

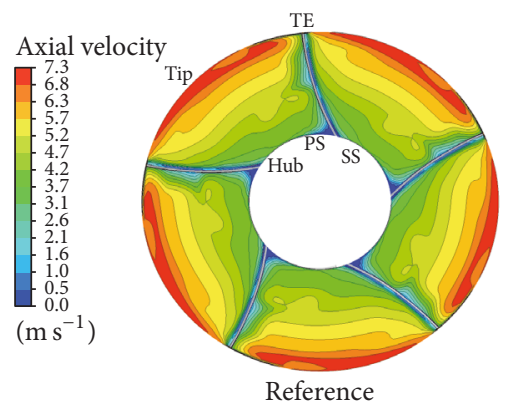

(c) Viewing point 2

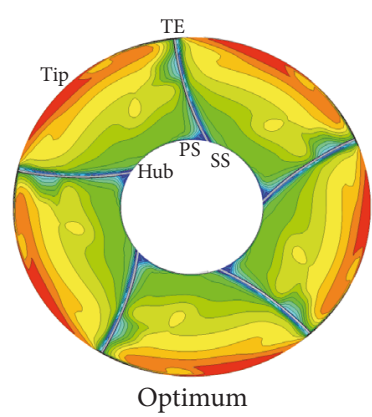

Optimum

FIGURE 14: Velocity distributions near the trailing edge of the front and rear runners.

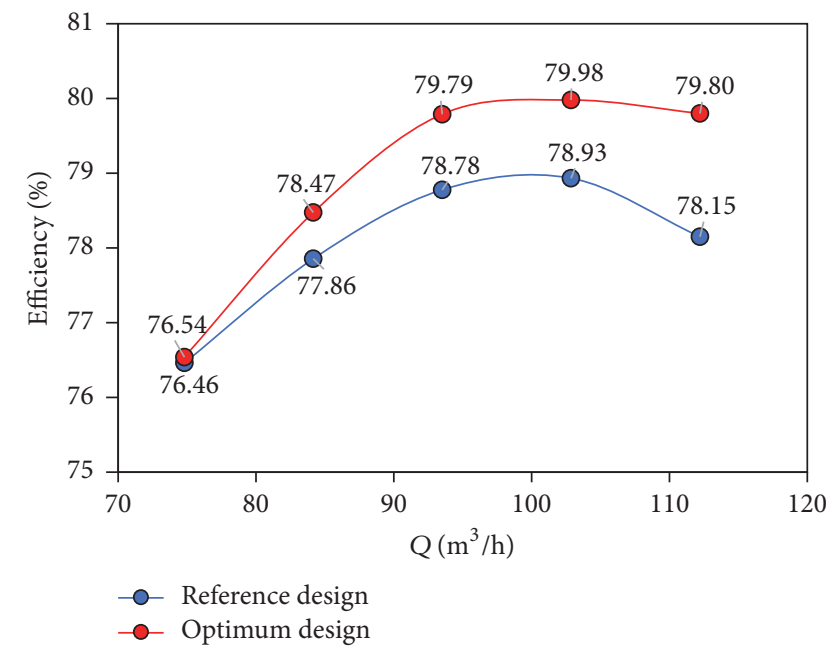

(a) Pump mode

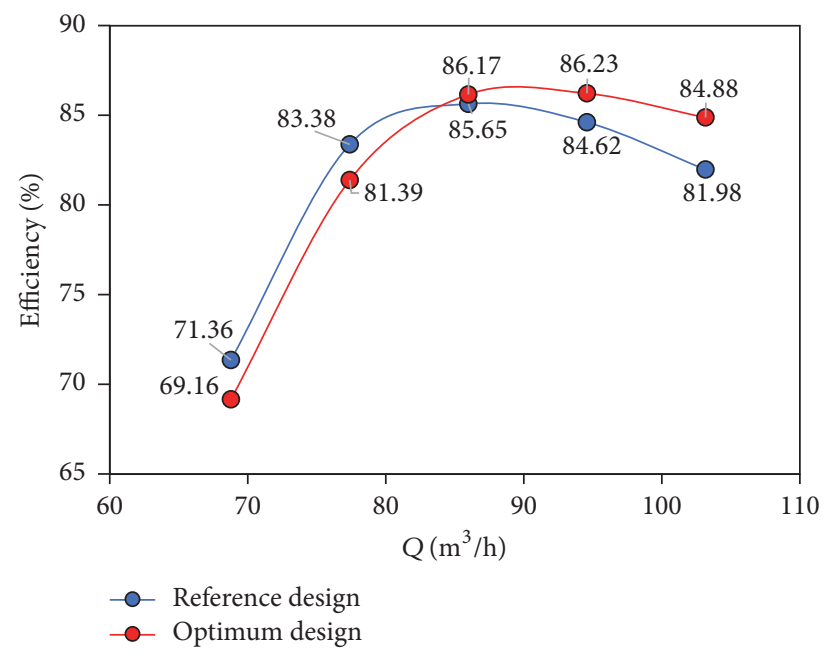

(b) Turbine mode

FIGURE 15: Variation of the pump and turbine mode efficiencies with flow rate.

mode efficiency was approximately twice the turbine mode efficiency. As the general design of a pump-turbine unit focuses on pump performance, the results of this study are very useful for the design of pump-turbine systems. Finally, the results of this work can be suggested as a guideline for the design of high-efficiency counter-rotating-type pumpturbine units.

\section{Nomenclature}

CFD: Computational fluid dynamics

D: $\quad$ Diameter of blade [mm]

Feff: Specific objective function value

g: Acceleration of gravity $\left[\mathrm{m} / \mathrm{s}^{2}\right]$

$H$ : Total head [m] 


\begin{tabular}{|c|c|}
\hline LHS: & Latin hypercube sampling \\
\hline$N t:$ & Total rotational speed [rpm] \\
\hline N11: & Coefficient related to the rotational speed \\
\hline PS: & Pressure side \\
\hline$P:$ & Power $[\mathrm{N}]$ \\
\hline P11: & Coefficient related to the power \\
\hline Q: & Volumetric flow rate $\left[\mathrm{m}^{3} / \mathrm{s}\right]$ \\
\hline RBNN: & Radial basis neural network \\
\hline Reference: & Reference design \\
\hline SST: & Shear stress transport \\
\hline SS: & Suction surface \\
\hline SQP: & Sequential quadratic programming \\
\hline$T:$ & Blade torque $[\mathrm{Nm}]$ \\
\hline TE: & Trailing edge \\
\hline$x, y$, and $z$ : & Orthogonal coordinate system \\
\hline$x 1:$ & 4B_hub variable $\left[{ }^{\circ}\right]$ \\
\hline$x 2:$ & $4 \mathrm{~B} \_$tip variable $\left[{ }^{\circ}\right]$ \\
\hline$\eta:$ & Dimensionless efficiency \\
\hline$\eta_{p}:$ & Pump efficiency [\%] \\
\hline$\eta_{t}:$ & Turbine efficiency [\%] \\
\hline 4B: & Impeller/runner with four blades \\
\hline 5B: & Impeller/runner with five blades \\
\hline 4B_hub: & $\begin{array}{l}\text { Hub profile blade angle of four-blade } \\
\text { impeller/runner }\end{array}$ \\
\hline 4B_tip: & $\begin{array}{l}\text { Tip profile blade angle of four-blade } \\
\text { impeller/runner }\end{array}$ \\
\hline$\rho:$ & Density $\left[\mathrm{kg} / \mathrm{m}^{3}\right]$ \\
\hline$\omega_{1}:$ & Weighting factors for the pump mode \\
\hline$\omega_{2}$ : & Weighting factors for the turbine mode. \\
\hline
\end{tabular}

\section{Conflicts of Interest}

The authors declare that they have no conflicts of interest.

\section{Acknowledgments}

This work was supported by a grant from the Demand-BasedPlatform R\&D Project of the Korea Institute of Industrial Technology (JA180011), which was funded by the Ministry of Science, ICT and Future Planning (MSIP). The authors gratefully acknowledge this support.

\section{References}

[1] T. Kanemoto, R. Kasahara, H. Honda, T. Miyaji, and J.-H. Kim, "Counter-rotating type pump-turbine unit stabilizing momentarily fluctuating power from renewable energy resources," in Proceedings of the ASME 2013 International Mechanical Engineering Congress and Exposition, IMECE 2013, San Diego, Calif, USA, November 2013.

[2] J.-H. Kim, R. Kasahara, T. Kanemoto et al., "Multiobjective optimization of a counterrotating type pump-turbine unit operated at turbine mode," Advances in Mechanical Engineering, vol. 2014, Article ID 467235, 2014.

[3] T. Kanemoto, S. Kimura, S. Ohba, and M. Satoh, "Smart control of axial flow pump performances by means of counter-rotating type (1st report, counter-rotating type and performances)," Nihon Kikai Gakkai Ronbunshu, B Hen/Transactions of the Japan Society of Mechanical Engineers, Part B, vol. 66, no. 651, pp. 2927-2933, 2000.
[4] S. Momosaki, S. Usami, S. Watanabe, and A. Furukawa, "Numerical simulation of internal flow in a contra-rotating axial flow pump," IOP Conference Series: Earth and Environmental Science, vol. 12, p. 012046, 2010.

[5] R. Kasahara, G. Takano, T. Murakami, T. Kanemoto, and K. Komaki, "Counter-Rotating Type Axial Flow Pump Unit," IOP Conference Series, Earth and Environmental Science, vol. 15, 042026 pages, 2012.

[6] T. Murakami and T. Kanemoto, "Counter-rotating type pumpturbine unit cooperating with wind power unit," Journal of Thermal Science, vol. 22, no. 1, pp. 7-12, 2013.

[7] T. Kanemoto and S. Oba, "Proposition of Unique Pumping System with Counter-Rotating Mechanism," International Journal of Rotating Machinery, vol. 10, no. 4, pp. 233-240, 2004.

[8] L. Cao, S. Watanabe, S. Momosaki, T. Imanishi, and A. Furukawa, "Low speed design of rear rotor in contra-rotating axial flow pump," The International Journal of Fluid Machinery and Systems, vol. 6, no. 2, pp. 105-112, 2013.

[9] J.-H. Kim, B.-M. Cho, S. Kim et al., "Design technique to improve the energy efficiency of a counter-rotating type pumpturbine," Journal of Renewable Energy, vol. 101, pp. 647-659, 2017.

[10] ANSYS CFX-14.5, , ANSYS CFX-Solver Theory Guide, ANSYS Inc, 2012.

[11] J.-W. Kim, J.-W. Suh, Y.-S. Choi et al., "Simultaneous efficiency improvement of pump and turbine modes for a counterrotating type pump-turbine," Advances in Mechanical Engineering, vol. 8, no. 11, pp. 1-14, 2016.

[12] K.-Y. Kim and M.-A. Moon, "Optimization of a stepped circular pin-fin array to enhance heat transfer performance," Heat and Mass Transfer, vol. 46, no. 1, pp. 63-74, 2009.

[13] Minitab Inc, "Minitab Statistical Software," in Release 14 for Windows, State College, PA, USA, 2013.

[14] JMP, The Statistical Discovery Software, Version 6.0.0, SAS Institute Inc, Cary, NC, USA, 2005.

[15] J.-H. Kim, B.-M. Cho, Y.-S. Kim et al., "Optimization of a single-channel pump impeller for wastewater treatment," The International Journal of Fluid Machinery and Systems, vol. 9, no. 4, pp. 370-381, 2016.

[16] J.-H. Kim and K.-Y. Kim, "Analysis and optimization of a vaned diffuser in a mixed flow pump to improve hydrodynamic performance," Journal of Fluids Engineering, vol. 134, no. 7, Article ID 71104, 2012.

[17] J. Kim, J. Choi, and K. Kim, "Surrogate Modeling for Optimization of a Centrifugal Compressor Impeller," The International Journal of Fluid Machinery and Systems, vol. 3, no. 1, pp. 29-38, 2010.

[18] L. Tan, S. Cao, and S. Gui, "Hydraulic design and pre-whirl regulation law of inlet guide vane for centrifugal pump," Science China Technological Sciences, vol. 53, no. 8, pp. 2142-2151, 2010.

[19] L. Tan, S. Cao, Y. Wang, and B. Zhu, "Direct and inverse iterative design method for centrifugal pump impellers," Proceedings of the Institution of Mechanical Engineers, Part A: Journal of Power and Energy, vol. 226, no. 6, pp. 764-775, 2012.

[20] L. Tan, B. Zhu, S. Cao, H. Bing, and Y. Wang, "Influence of blade wrap angle on centrifugal pump performance by numerical and experimental study," Chinese Journal of Mechanical Engineering, vol. 27, no. 1, pp. 171-177, 2014.

[21] T. Lei, Y. Zhiyi, X. Yun, L. Yabin, and C. Shuliang, "Role of blade rotational angle on energy performance and pressure fluctuation of a mixed-flow pump," Proceedings of the Institution of Mechanical Engineers, Part A: Journal of Power and Energy, vol. 231, no. 3, pp. 227-238, 2017. 
[22] Y. Xu, L. Tan, S. Cao, and W. Qu, "Multiparameter and multiobjective optimization design of centrifugal pump based on orthogonal method," Proceedings of the Institution of Mechanical Engineers, Part C: Journal of Mechanical Engineering Science, vol. 231, no. 14, pp. 2569-2579, 2017.

[23] The Math Work Inc. MATLAB ${ }^{\circledR}, 2015$, The Language of Technical Computing, Revised for Version 8.6 (R2015b).

[24] Y. CHOI, J. LIM, Y. KIM, and Y. LEE, "Performance and Internal Flow Characteristics of a Cross-Flow Hydro Turbine by the Shapes of Nozzle and Runner Blade," Journal of Fluid Science and Technology, vol. 3, no. 3, pp. 398-409, 2008. 


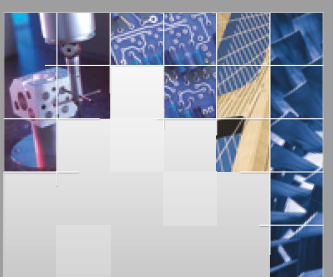

\section{Enfincering}
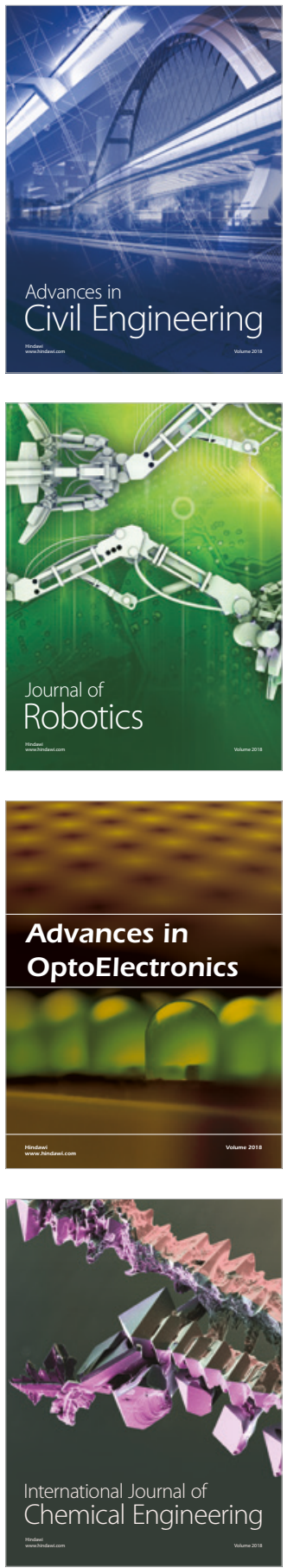

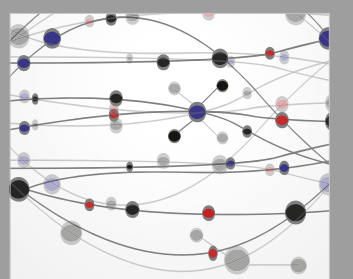

\section{Rotating \\ Machinery}

The Scientific World Journal

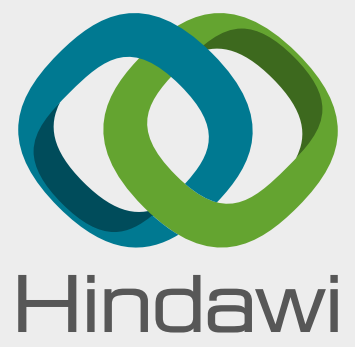

Submit your manuscripts at

www.hindawi.com
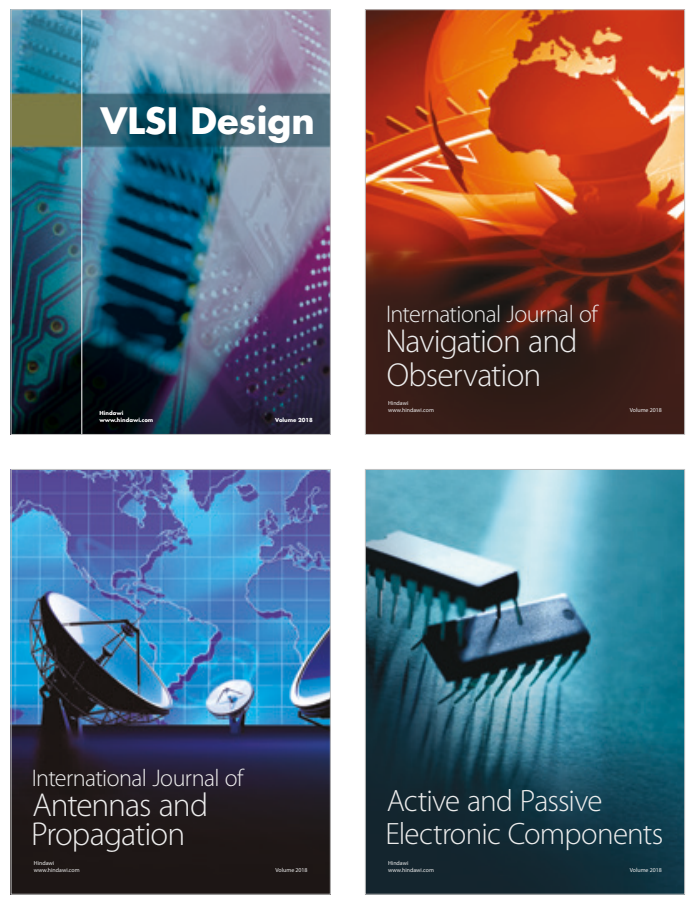
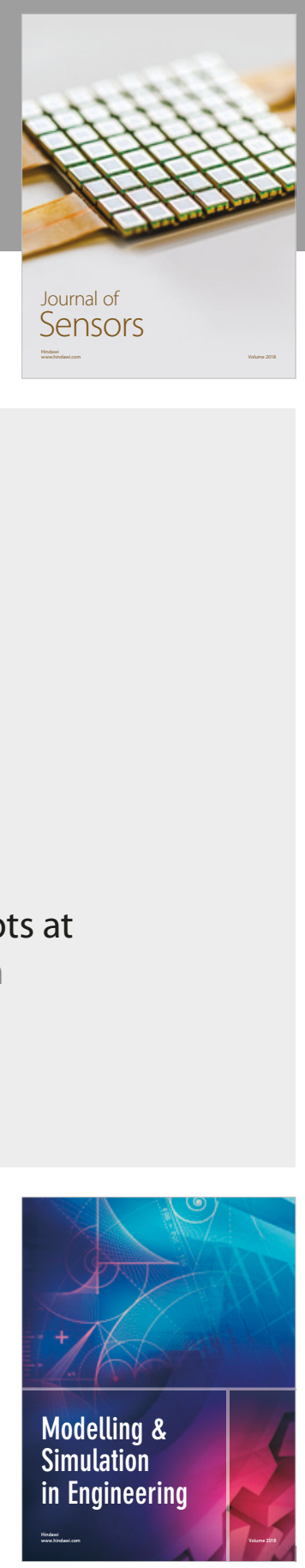

\section{Advances \\ Multimedia}
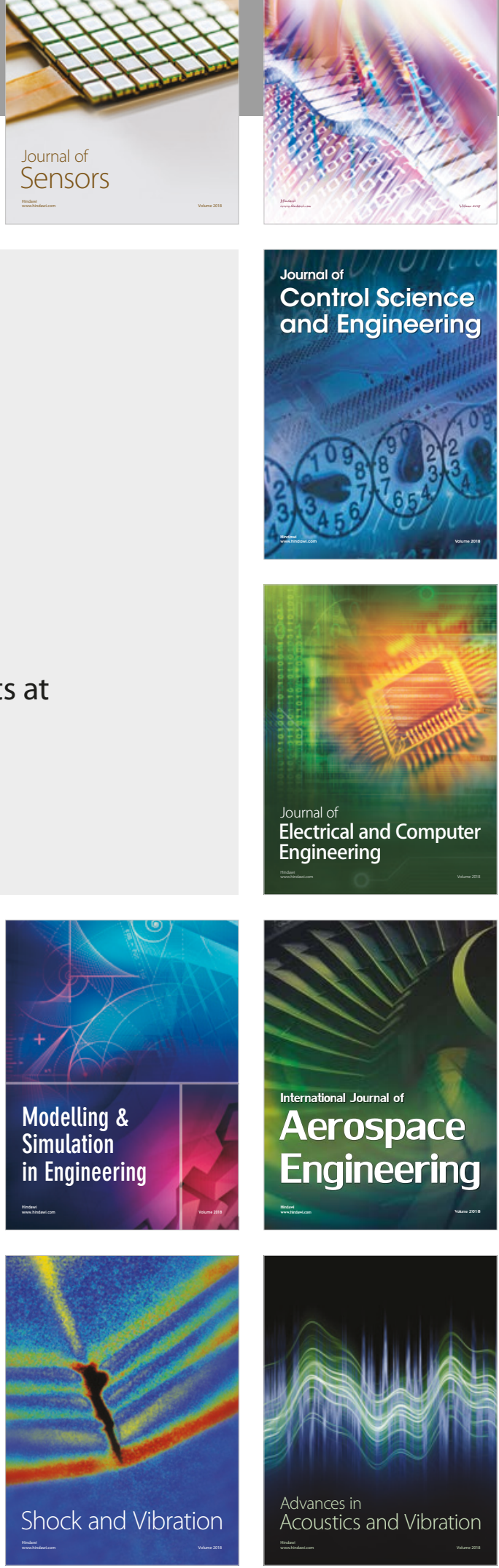